\title{
Influence of Lead on the Interpretation of Bone Samples with Laser-Induced Breakdown Spectroscopy
}

\author{
Abdolhamed Shahedi, ${ }^{1}$ Esmaeil Eslami, ${ }^{1}$ and Mohammad Reza Nourani ${ }^{2}$ \\ ${ }^{1}$ Department of Physics, Iran University of Science and Technology, Narmak, Tehran 16846-13114, Iran \\ ${ }^{2}$ Tissue Engineering Division, Biotechnology Research Center, Baqiyatallah University of Medical Sciences, Tehran, Iran \\ Correspondence should be addressed to Esmaeil Eslami; eeslami@iust.ac.ir
}

Received 16 December 2015; Revised 10 March 2016; Accepted 6 April 2016

Academic Editor: Yu Shang

Copyright (C) 2016 Abdolhamed Shahedi et al. This is an open access article distributed under the Creative Commons Attribution License, which permits unrestricted use, distribution, and reproduction in any medium, provided the original work is properly cited.

\begin{abstract}
This study is devoted to tracing and identifying the elements available in bone sample using Laser-Induced Breakdown Spectroscopy (LIBS). The bone samples were prepared from the thigh of laboratory rats, which consumed $325.29 \mathrm{~g} / \mathrm{mol}$ lead acetate having $4 \mathrm{mM}$ concentration in specified time duration. About 76 atomic lines have been analyzed and we found that the dominant elements are Ca I, Ca II, Mg I, Mg II, Fe I, and Fe II. Temperature curve and bar graph were drawn to compare bone elements of group B which consumed lead with normal group, group A, in the same laboratory conditions. Plasma parameters including plasma temperature and electron density were determined by considering Local Thermodynamic Equilibrium (LTE) condition in the plasma. An inverse relationship has been detected between lead absorption and elements like Calcium and Magnesium absorption comparing elemental values for both the groups.
\end{abstract}

\section{Introduction}

Nowadays, an increasing spread of polluting industries, the pollution caused by toxic metals, and the hazards on human health are crystal clear to everyone. Thus detecting these pollutants and their effects on biological organisms is of great importance. Laser-Induced Breakdown Spectroscopy (LIBS) method has attracted much attention of many researchers due to its properties, unique capabilities such as low cost and minimal time duration of preparing the sample, prompt and simultaneous analysis of multielements, capability of being used in all three states of materials, and its nondestructive and noncontact nature $[1,2]$. This method has been successfully used to identify corpses, bones, and humans' fossils or mummies remaining from centuries. It determines characteristic backgrounds like age, sex, race, and stature of bodies [3]. Clinical application of Laser-Induced Breakdown Spectroscopy to the analysis of teeth and dental materials used the pulsed lasers for controlled material ablation. This method is suggested as an alternative to mechanical drilling for the removal of caries and in tooth modification. Spectral analysis of the ablated plasma can be exploited to monitor precisely the laser drilling process in vivo and in real time [4, 5]. LIBS procedure proposes a new technique for diagnosing the presence or occurrence of cancer accurately and safely. It is now apparent that the malignant tumors can be predicted via detection of Calcium, Potassium, and Copper in body [6]. The method was also used to detect the elements of newborn heart muscles by reviewing elements such as Potassium, Calcium, and Sodium [7]. Analyzing biological seminal fluid [8], detecting pathogenic bacteria and pathogens [9], and so forth are among other applications of this method.

The presented technique depends on the interaction between the laser and the soft and hard biological surfaces in order to induce plasma. The plasma formation results from the matrix effects initiated by the absorption of the laser energy by the ablated material [2]. When the plasma expands in an ambient air, relaxation of the plasma plume by different processes-one of which is the recombination of the free electrons with the positive ions-occurs [10]. This recombination is a radiative process, which provides a continuum emission in addition to the bremsstrahlung. Another radiative process is the atomic emissions due to transitions between the different energy levels of an element from 


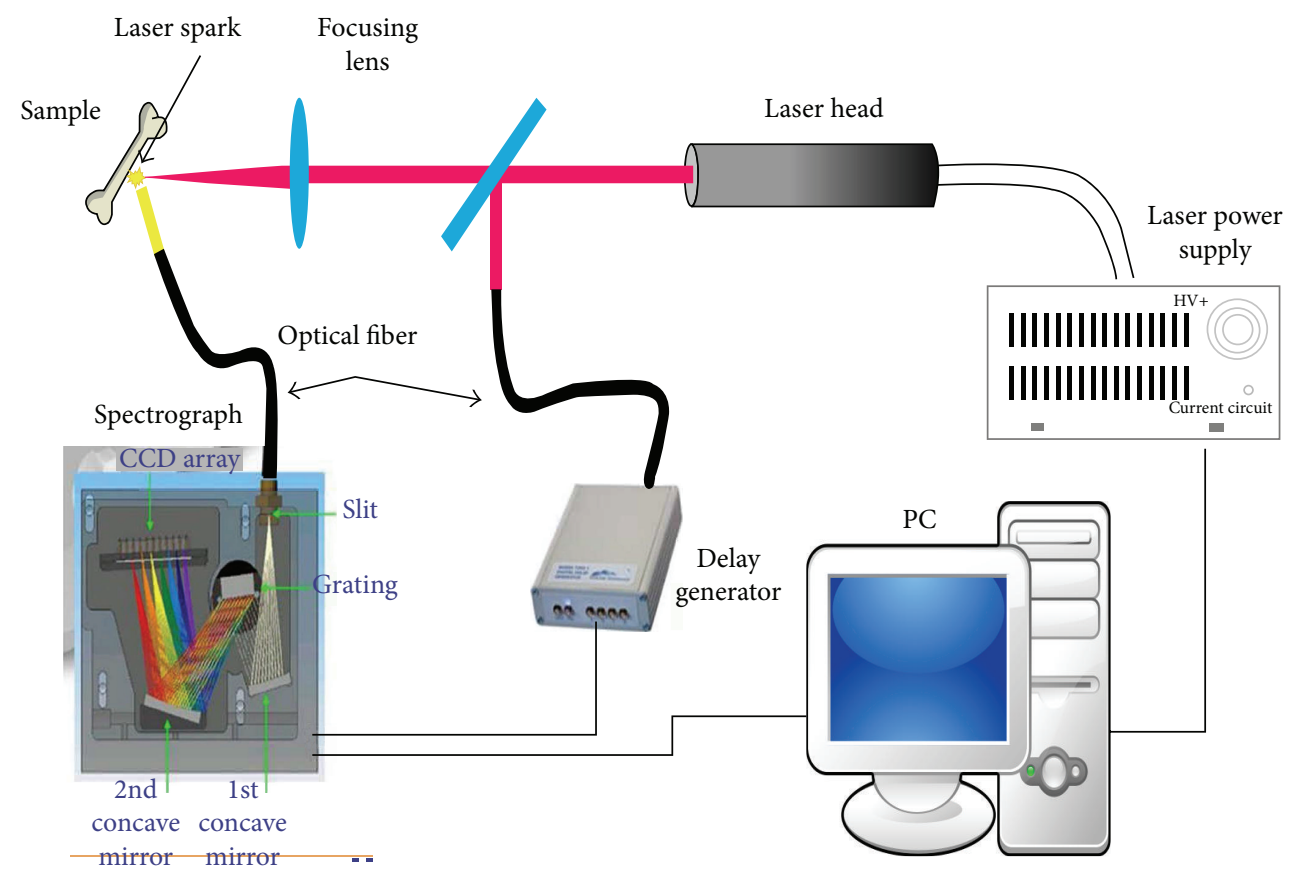

FIGURE 1: Schematic of the LIBS setup.

which spectrometric measurement can provide qualitative information on the atomic composition of the investigated biological samples. In addition, LIBS can also be used to provide information about the relative quantitative elemental composition of the samples. This is achieved by investigating the ratio between the intensity levels of the atomic emission lines: high concentrations of an element yield a higher intensity of the characteristic elemental emission spectra [11,12].

In this study, we attempted to employ this method to differentiate between two groups of rates based mainly on the statistical analysis of the collected spectra. These spectra intrinsically possess information of the different concentration levels of the elements found in both the groups.

\section{Methods and Materials}

2.1. Test Layout. The experimental setup is schematically shown in Figure 1. It consists of a Nd:Yag laser having $10 \mathrm{~ns}$ pulse width at $1064 \mathrm{~nm}$ wavelength, $2 \mathrm{~Hz}$ pulse repetition frequency, and $160 \mathrm{~mJ}$ energy. To eliminate bremsstrahlung radiation in early stage when plasma is generated, and to have atomic spectrum with the highest ratio of signal to noise, different time intervals in plasma radiation are required. A delay time between laser pulse and data recording by photodiode was about $10 \mu \mathrm{s}$. As illustrated in Figure 1, a part of laser light is reflected toward photodiode by a half-silvered mirror (reflects about $4 \%$ of light) which lies in a 45 -degree angle in line with light and delay contributor starts the camera by sending a pulse. Laser beam is focused on the surface of the sample located at the focal length of the converging lens with $f=10 \mathrm{~cm}$. An optical fiber locates at 45 degrees with beams in optimal distance from the location where plasma was generated (to avoid saturation) and transmits the light resulting

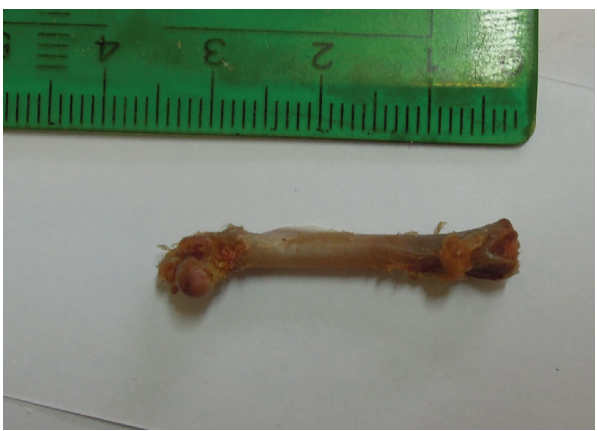

FIgure 2: An example of rat's bone.

from the plasma to the 2D intensified CCD (Andor iStar, DH720) through a Czerny-Turner spectrograph (Chromex, 500 IS) in the wavelength range of $115-920 \mathrm{~nm}$. LIBS spectra were collected from 10 different spots of each sample; 10 spectra were collected from each spot. These spectra enable us to analyze the sample quantitatively and quantitatively. To obtain ratio of signal to high noise, best conditions such as delay time and optical field of view were optimized.

2.2. Sample Preparation. Female rats with average age of four weeks with same race and conditions were chosen for preparing bone samples. Ten rats were divided into two equal groups. Group A received $250 \mathrm{~mL}$ distilled water including lead salts (lead acetate $325.29 \mathrm{~g} / \mathrm{mol}$ ) with $4 \mathrm{mM}$ concentration daily and group B received only $250 \mathrm{~mL}$ distilled water with no additives daily for 50 days. Most portion of lead is absorbed in bones [13]. So the left legs of the rats were split up and cleaned. Since almost all portions of lead injected to 

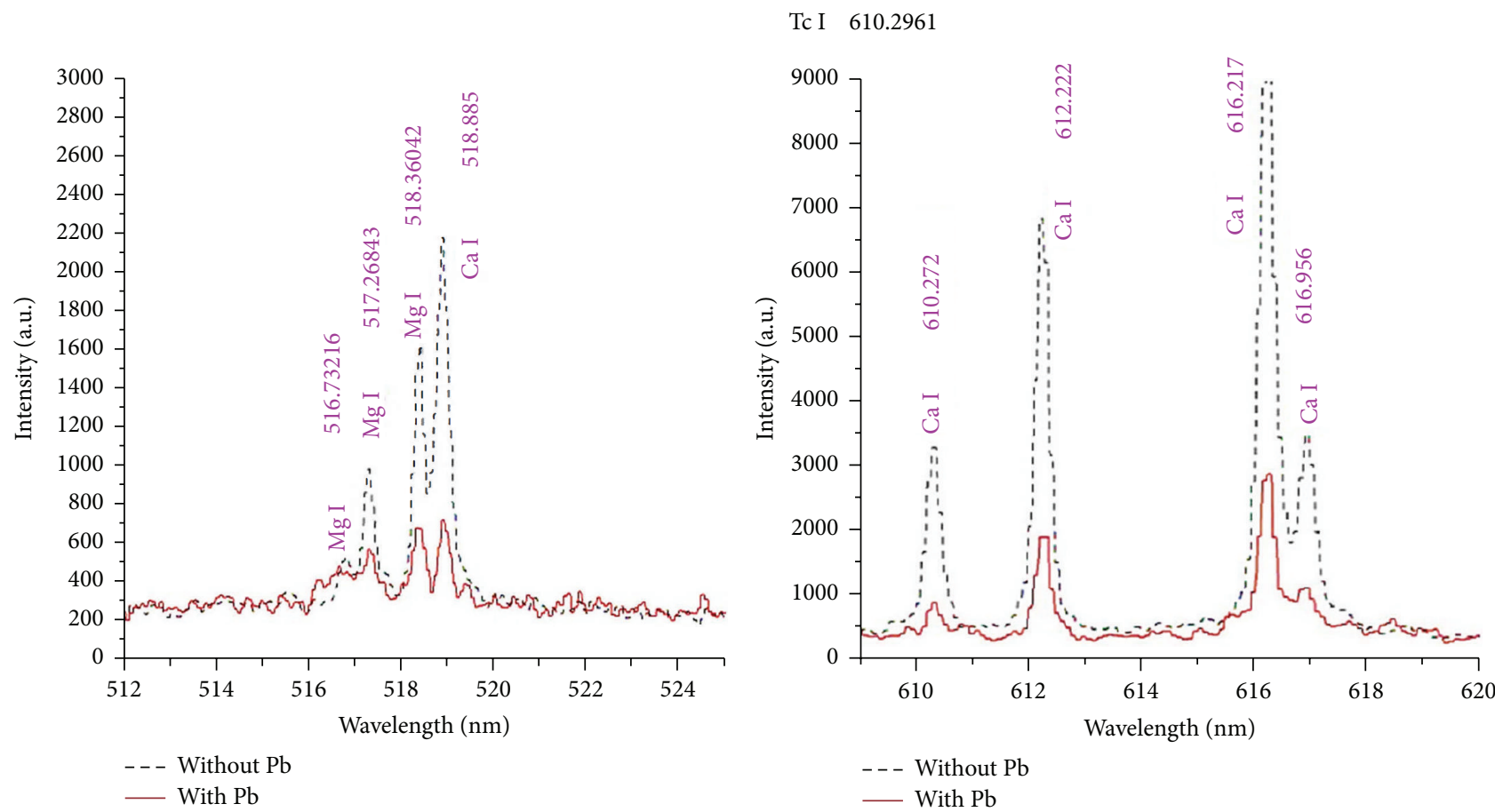

FIgURE 3: Typical mean LIBS spectra in both groups.

the body were absorbed in bone, they influence absorption of other elements in bone according to the procedure to prepare for laser pulse irradiation (Figure 2).

\section{Plasma Characteristics}

The LIBS spectra collected from the samples were processed from the raw data using the ORIGIN software. Figure 3 shows the mean spectra (mean value and standard deviation) of 10 bone spectra of both groups. To exemplify, the most prominent peaks existing in the spectra of both samples were used to show the standard deviation of all of the 10 spot-measurements. The elements with prominent emissions common to both bone types, found under the measurement conditions of this study, were $\mathrm{Ca}, \mathrm{Mg}$, and $\mathrm{Fe}$. The LIBS spectra of group B exhibit more prominent atomic spectral lines than those of group A. The identification of the atomic lines is based on [14, 15]. As can be seen in this figure a significant decrease of $\mathrm{Mg}$ and $\mathrm{Ca}$ can be observed due to lead consumption. Note that during all experiments an intense line on $\mathrm{Pb} \mathrm{I}$ at $405.78 \mathrm{~nm}$ was observed. As illustrated in Figure 4, its intensity is increased with lead consummation in bone. However, our analysis is mainly focused on the effect of Pd on other elements.

3.1. Plasma Temperature. Plasma temperatures are often determined from the measurement of ratios of the intensities of neutral to neutral lines, usually for the same element. The line intensities are combined with the Boltzmann equation to determine

$$
\ln \left(\frac{I \lambda_{k i}}{A_{k i} g_{k}}\right)=\ln \left(\frac{h c}{4 \pi} \frac{N_{0}}{U(T)}\right)-\frac{E_{k}}{K T_{\mathrm{exc}}},
$$

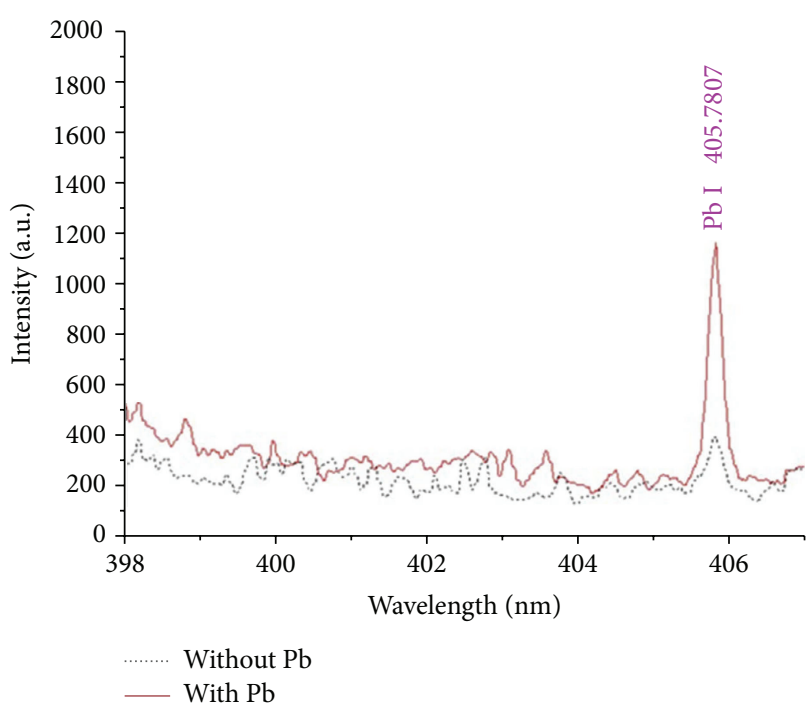

Figure 4: Typical lead spectrum at $405.78 \mathrm{~nm}$.

where $I$ is the intensity of the spectral line, $\lambda_{k i}$ is the wavelength of the transition from level $k$ to $i, A_{k i}$ is the transition probability, $g_{k}$ is the statistical weight, $E_{k}$ is the energy value of higher level, and $T_{\mathrm{exc}}$ is the excitation temperature. Thus, a plot of the above equation versus the energy of the upper level $E_{j}$ yields a straight line called Boltzmann plot. Its slope equals $-\left(K T_{\text {exc }}\right)^{-1}$ [16]. In this work, the plasma temperature was determined by using the total intensity of the different strong lines as $\mathrm{Fe}, \mathrm{Mg}$, and $\mathrm{Ca}$ in the visible region. Figure 5 shows the plasma temperature 

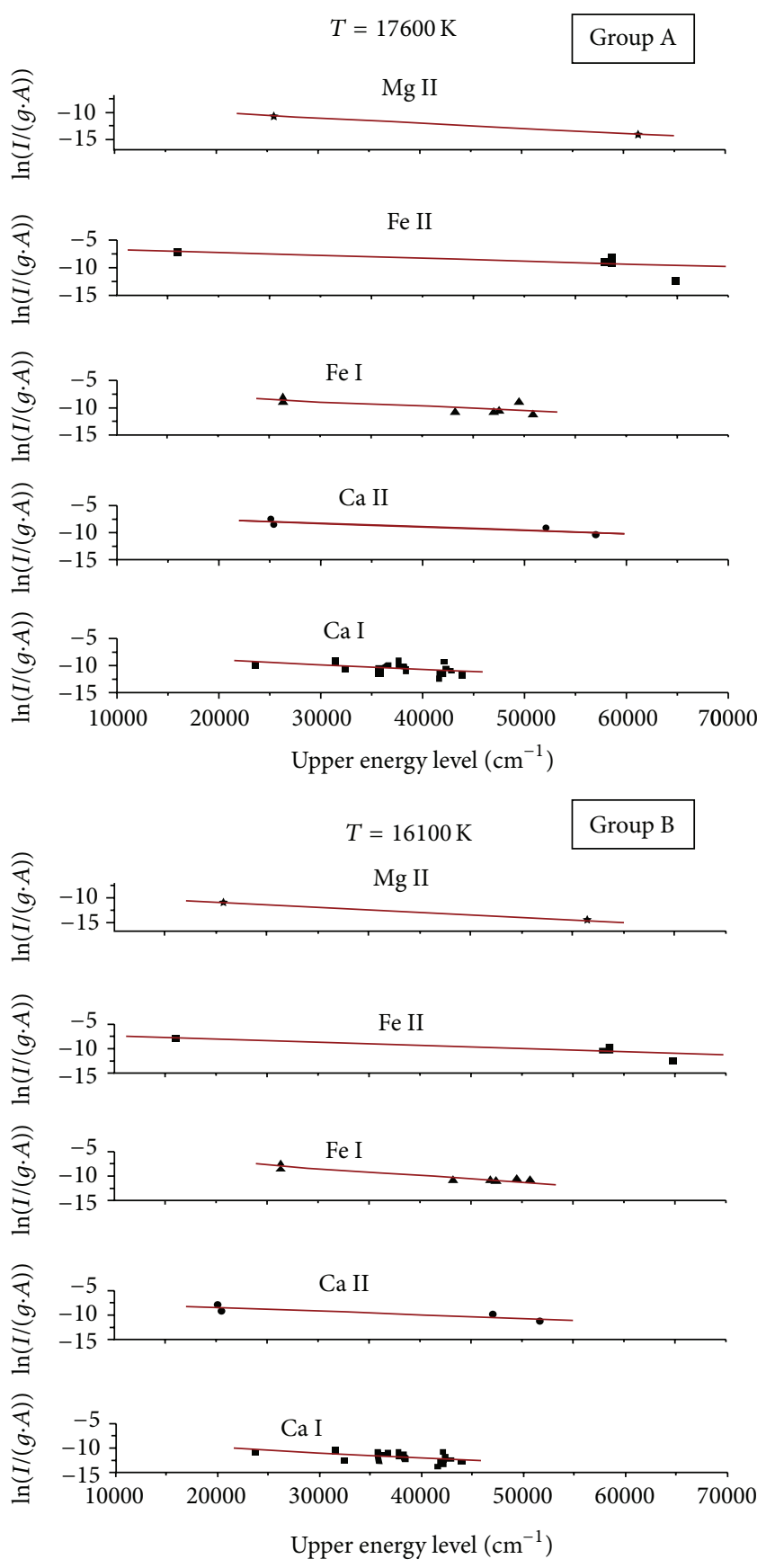

Figure 5: Boltzmann plots for different elements present in group $\mathrm{A}$ and group $\mathrm{B}$.

obtained for both the groups. The results are summarized in Table 1.

3.2. Electron Density. Plasma near the LTE condition could be characterized by a single temperature describing the distribution of species in energy levels, the population of ionization stages, or the kinetic energy of electrons, ions, and atoms. In this case, the excitation temperature would be the same as the plasma temperature. According to the SahaBoltzmann equation the electron density can be derived from
TABLE 1: Plasma temperature and electron density for both groups.

\begin{tabular}{lcc}
\hline Sample & Plasma temperature $(\mathrm{K})$ & Electron density $\left(\mathrm{cm}^{-3}\right)$ \\
\hline With $\mathrm{Pb}$ & $17613 \pm(14 \%)$ & $9 \times 10^{15}$ \\
Without $\mathrm{Pb}$ & $16140 \pm(18 \%)$ & $10 \times 10^{15}$ \\
\hline
\end{tabular}

the intensity ratio of two lines corresponding to different ionization stages of the same element $[17,18]$ :

$$
n_{e}=\frac{2\left(2 \pi m_{e} k T\right)^{3 / 2}}{h^{3}} \frac{I_{m n}^{\mathrm{I}} A_{j k} g_{j}^{\mathrm{II}}}{I_{j k}^{\mathrm{II}} A_{m n} g_{m}^{\mathrm{I}}} e^{-\left(E_{\mathrm{ion}}+E_{j}^{\mathrm{II}}-E_{m}^{\mathrm{I}}\right) / K T},
$$

where $E_{m}$ and $E_{j}$ are the upper level energies of neutral and single ionized transitions. $E_{\text {ion }}$ is the ionization energy and $n_{e}$ is the electron density. In practice, thermodynamic equilibrium is really hard to achieve in the whole area while it can exist in fine regions of plasma which are referred to as Local Thermodynamic Equilibrium (LTE). This condition is normally reached during adequate number of collisions where the energy is distributed more equally between colliding particles with the same masses. Thus, LTE may exist at high electron density limit given by McWhirter criterion $[19,20]$ :

$$
n_{e}\left(\mathrm{~cm}^{3}\right) \geq 1.6 \times 10^{12}\left[T_{\mathrm{exc}}(\mathrm{K})\right]^{1 / 2}[\Delta E(\mathrm{eV})]^{3},
$$

where $\Delta E$ is the energy difference between the two levels [21]. Table 1 shows an estimation of the electron density for both groups. The electron density was calculated using the above standard relation. We based our estimate on the $\mathrm{Ca}$ line at $452.69 \mathrm{~nm}$; its spectroscopic parameters are tabulated in [19]. An equality expression related to the electron density was used to estimate whether LTE is likely to prevail in our measurements. The value $4.5 \times 10^{15}\left(\mathrm{~cm}^{-3}\right)$, which, according to $[12,19]$, is needed for LTE to exist, is well below the values encountered in our experiments. This suggests that the analytical measurements in our study were most likely carried out under LTE conditions.

\section{Qualitative Analysis of Elements}

The following are the dominant elements available in both samples. The elements with prominent emissions common to both bone types are $\mathrm{Ca}, \mathrm{Mg}$, and $\mathrm{Fe}$. The content of these elements in bone is illustrated in Figure 6 for both groups.

Previous study shows that the Calcium (Ca I, Ca II) is the main source for the consumption of lead in bone [22]. This effect is clearly observed in Figure 3. Although the lead concentration is augmented itself, the portion of lead is consumed via chemical reactions to reduce Calcium. The results for Magnesium (Mg I, Mg II) are similar to Calcium. Magnesium like Calcium competes with lead for absorption in bone. So as expected, $\mathrm{Mg}$ I and $\mathrm{Mg}$ II decreased in sample of group A [23]. There is irregular reduction process for absorption in Fe I and Fe II. Unlike Ca and $\mathrm{Mg}$, Iron element increased in some recorded wavelengths when the rats consumed lead. This behavior was observed in the 


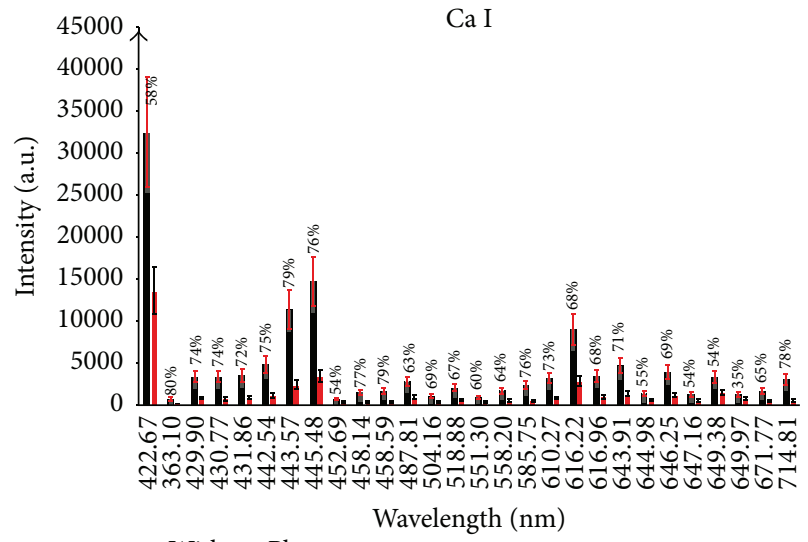

- Without $\mathrm{Pb}$

with $\mathrm{Pb}$

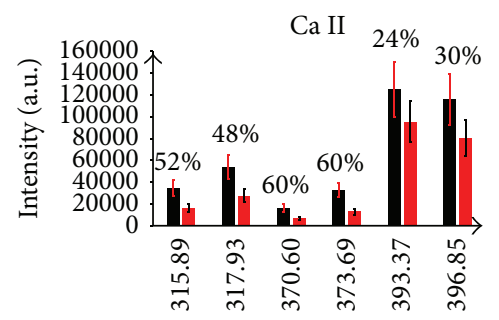

Wavelength (nm)

- Without $\mathrm{Pb}$

- With $\mathrm{Pb}$

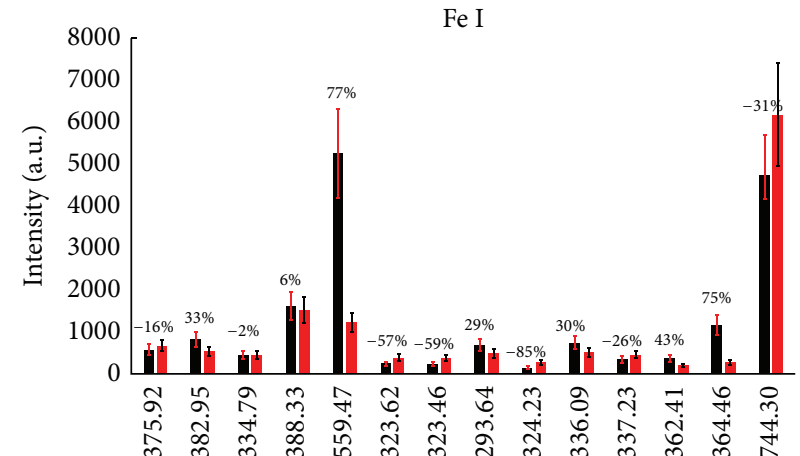

Wavelength $(\mathrm{nm})$

- Without $\mathrm{Pb}$

a With $\mathrm{Pb}$

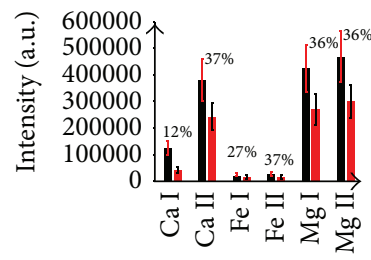

Wavelength $(\mathrm{nm})$

- Without $\mathrm{Pb}$

- With $\mathrm{Pb}$

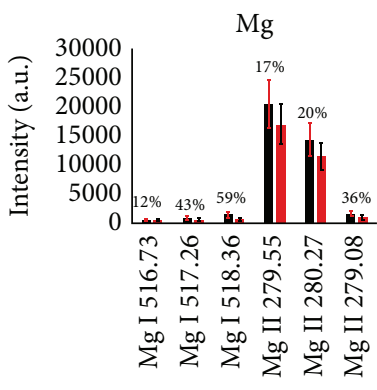

Wavelength (nm)

- Without $\mathrm{Pb}$

- With $\mathrm{Pb}$
Fe I

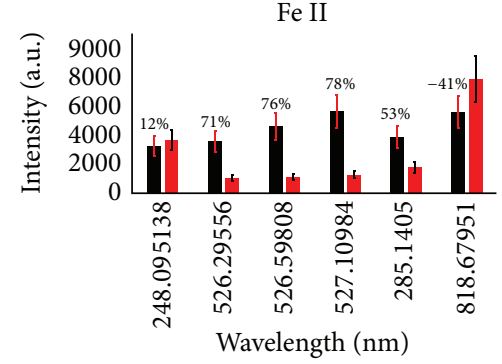

- Without $\mathrm{Pb}$

- With $\mathrm{Pb}$

FIGURE 6: Comparison of relative intensity of different element presented in both groups. 
previous work [24]. However, a decrease in Fe element at some lines is observed for group A.

In conclusion, results revealed that temperature and electron density of plasma resulting from laser beam are similar for both lead and nonlead groups and they obey Local Thermodynamic Equilibrium (LTE) conditions. The effect of its absorption in elements such as Calcium, Magnesium, and Fe had been recognized, although Laser-Induced Breakdown Spectroscopy (LIBS) method for measuring absorbed lead having such concentration in bone lacks proper performance. Qualitative comparison in value of elements in both the groups revealed that values of $\mathrm{Ca}$ I and $\mathrm{Ca}$ II and $\mathrm{Mg}$ I and Mg II were decreased by absorbing lead. Although there is an indirect relation for Fe concentration with absorption of lead at various wavelengths, it revealed that values of minerals such as Fe I and Fe II were globally decreased.

\section{Competing Interests}

The authors declare that they have no competing interests.

\section{References}

[1] K. Song, Y.-I. Lee, and J. Sneddon, "Applications of laserinduced breakdown spectrometry," Applied Spectroscopy Reviews, vol. 32, no. 3, pp. 183-235, 1997.

[2] D. A. Cremers and L. J. Radziemski, Laser Induced Breakdown Spectroscopy, Cambridge University Press, 2006.

[3] M. Z. Martin, N. Labbé, N. André et al., "High resolution applications of laser-induced breakdown spectroscopy for environmental and forensic applications," Spectrochimica Acta Part B: Atomic Spectroscopy, vol. 62, no. 12, pp. 1426-1432, 2007.

[4] O. Samek, D. C. S. Beddows, H. H. Telle, G. W. Morris, M. Liska, and J. Kaiser, "Quantitative analysis of trace metal accumulation in teeth using laser-induced breakdown spectroscopy," Applied Physics A, vol. 69, no. 1, supplement, pp. S179-S182, 1999.

[5] O. Samek, H. H. Telle, and D. C. S. Beddows, "Laser-induced breakdown spectroscopy: a tool for real-time, in vitro and in vivo identification of carious teeth," BMC Oral Health, vol. 1, no. 1, article 1, 2001.

[6] A. Kumar, F.-Y. Yueh, J. P. Singh, and S. Burgess, "Characterization of malignant tissue cells by laser-induced breakdown spectroscopy," Applied Optics, vol. 43, no. 28, pp. 5399-5403, 2004.

[7] H. P. de Souza, E. Munin, L. P. Alves, M. L. Redígolo, and Marcos, "Laser-induced breakdown spectroscopy in a biological tissue," in Proceedings of the 26th Conference of ENFMC-Annals of Optics, vol. 5, pp. 1-4, 2003.

[8] Z. Abdel-Salam and M. A. Harith, "Laser spectrochemical characterization of semen," Talanta, vol. 99, pp. 140-145, 2012.

[9] S. J. Rehse, H. Salimnia, and A. W. Miziolek, "Laser-induced breakdown spectroscopy (LIBS): an overview of recent progress and future potential for biomedical applications," Journal of Medical Engineering \& Technology, vol. 36, no. 2, pp. 77-89, 2012.

[10] D. A. Cremers and R. C. Chinni, "Laser-induced breakdown spectroscopy - capabilities and limitations," Applied Spectroscopy Reviews, vol. 44, no. 6, pp. 457-506, 2009.

[11] A. K. Myakalwar, S. Sreedhar, I. Barman et al., "Laser-induced breakdown spectroscopy-based investigation and classification of pharmaceutical tablets using multivariate chemometric analysis," Talanta, vol. 87, no. 1, pp. 53-59, 2011.

[12] O. Samek, M. Liska, J. Kaiser et al., "Laser ablation for mineral analysis in the human body: integration of LIFS with LIBS," in Biomedical Sensors, Fibers, and Optical Delivery Systems, vol. 3570 of Proceedings of SPIE, International Society for Optics and Photonics, 1999.

[13] T. Fortune and D. I. Lurie, "Chronic low-level lead exposure affects the monoaminergic system in the mouse superior olivary complex," Journal of Comparative Neurology, vol. 513, no. 5, pp. 542-558, 2009.

[14] A. Zaidel, Tables of Spectral Lines, Springer Science \& Business Media, 2013.

[15] J. E. Sansonetti, W. C. Martin, and S. Young, "Handbook of basic atomic spectroscopic data," Journal of Physical and Chemical Reference Data, vol. 34, no. 4, pp. 1559-2260, 2005.

[16] S. Pandhija and A. K. Rai, "In situ multielemental monitoring in coral skeleton by CF-LIBS," Applied Physics B, vol. 94, no. 3, pp. 545-552, 2009.

[17] D. A. Cremers and L. J. Radziemski, "Basics of the LIBS plasma," in Handbook of Laser-Induced Breakdown Spectroscopy, pp. 2352, John Wiley \& Sons, 2006.

[18] S. Z. Mortazavi, P. Parvin, M. R. Mousavi Pour, A. Reyhani, A. Moosakhani, and S. Moradkhani, "Time-resolved evolution of metal plasma induced by Q-switched Nd:YAG and ArF-excimer lasers," Optics \& Laser Technology, vol. 62, pp. 32-39, 2014.

[19] H. R. Griem, Principles of Plasma Spectroscopy, vol. 2, Cambridge University Press, 2005.

[20] R. McWhirter, R. Huddlestone, and S. Leonard, Plasma Diagnostic Techniques, Academic, New York, NY, USA, 1965.

[21] A. F. M. Y. Haider and Z. H. Khan, "Determination of Ca content of coral skeleton by analyte additive method using the LIBS technique," Optics \& Laser Technology, vol. 44, no. 6, pp. 16541659, 2012.

[22] J. C. Barton, M. E. Conrad, L. Harrison, and S. Nuby, "Effects of calcium on the absorption and retention of lead," The Journal of Laboratory and Clinical Medicine, vol. 91, no. 3, pp. 366-376, 1978.

[23] A. A. Van Barneveld and C. J. A. Van den Hamer, "Influence of $\mathrm{Ca}$ and $\mathrm{Mg}$ on the uptake and deposition of $\mathrm{Pb}$ and $\mathrm{Cd}$ in mice," Toxicology and Applied Pharmacology, vol. 79, no. 1, pp. 1-10, 1985.

[24] I. K. Robertson and M. Worwood, "Lead and iron absorption from rat small intestine: the effect of dietary Fe deficiency," British Journal of Nutrition, vol. 40, no. 2, pp. 253-260, 1978. 

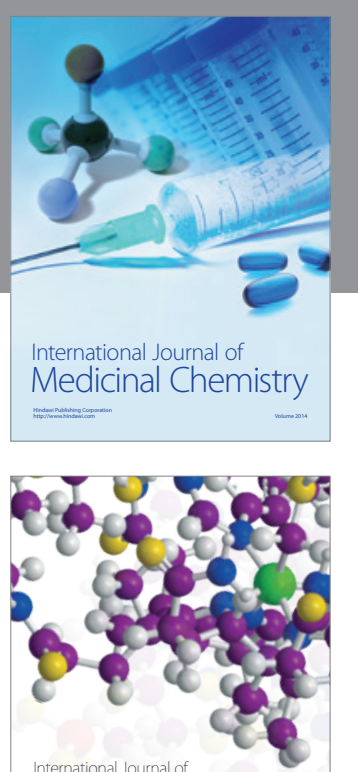

Carbohydrate Chemistry

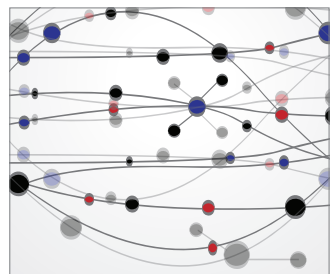

The Scientific World Journal
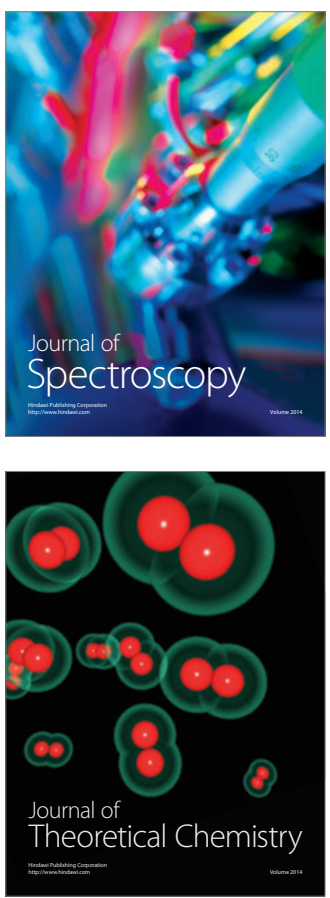
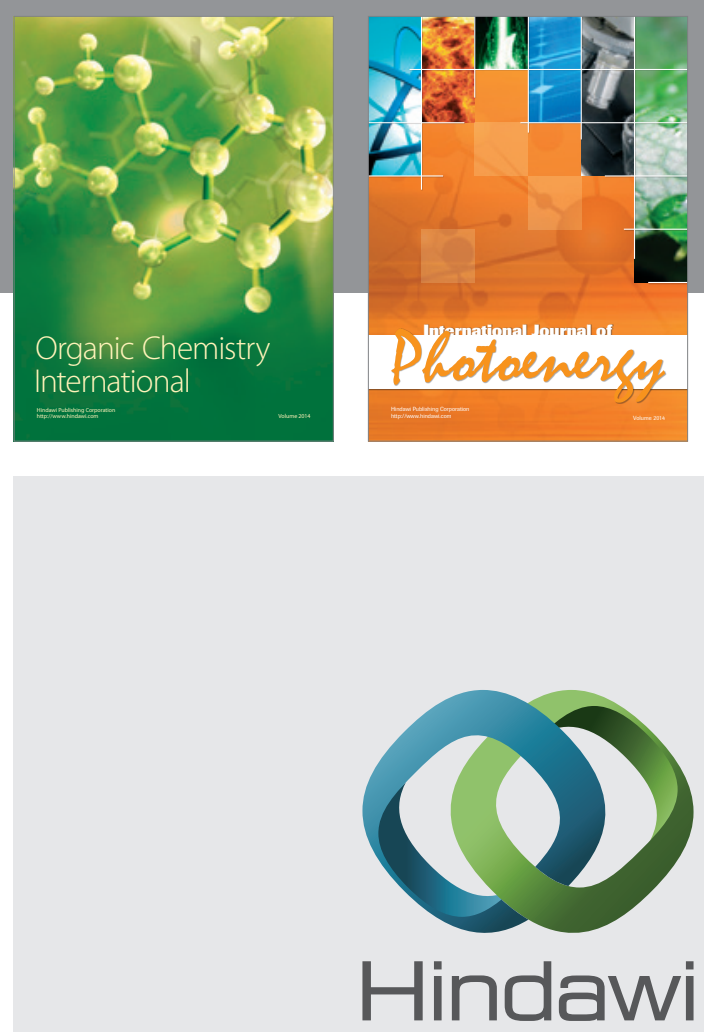

Submit your manuscripts at

http://www.hindawi.com

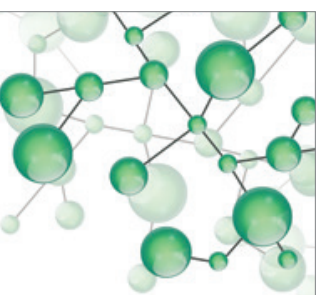

International Journal of

Inorganic Chemistry

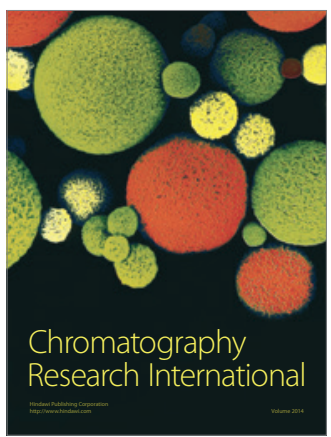

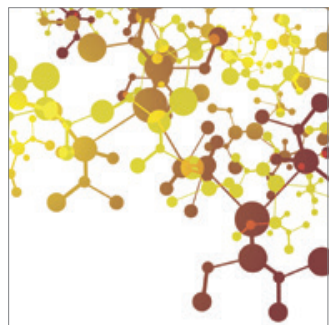

Applied Chemistry
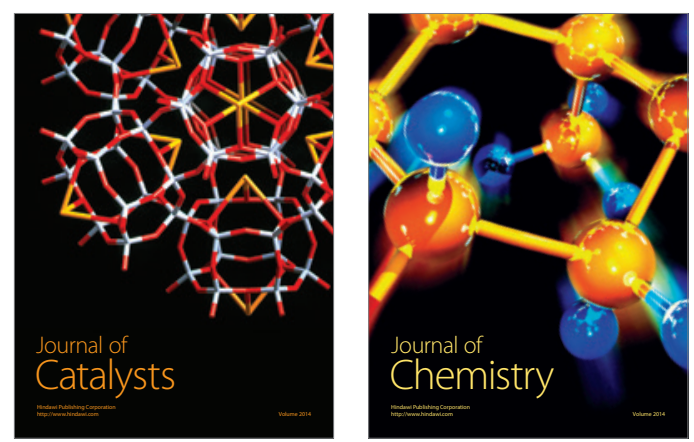
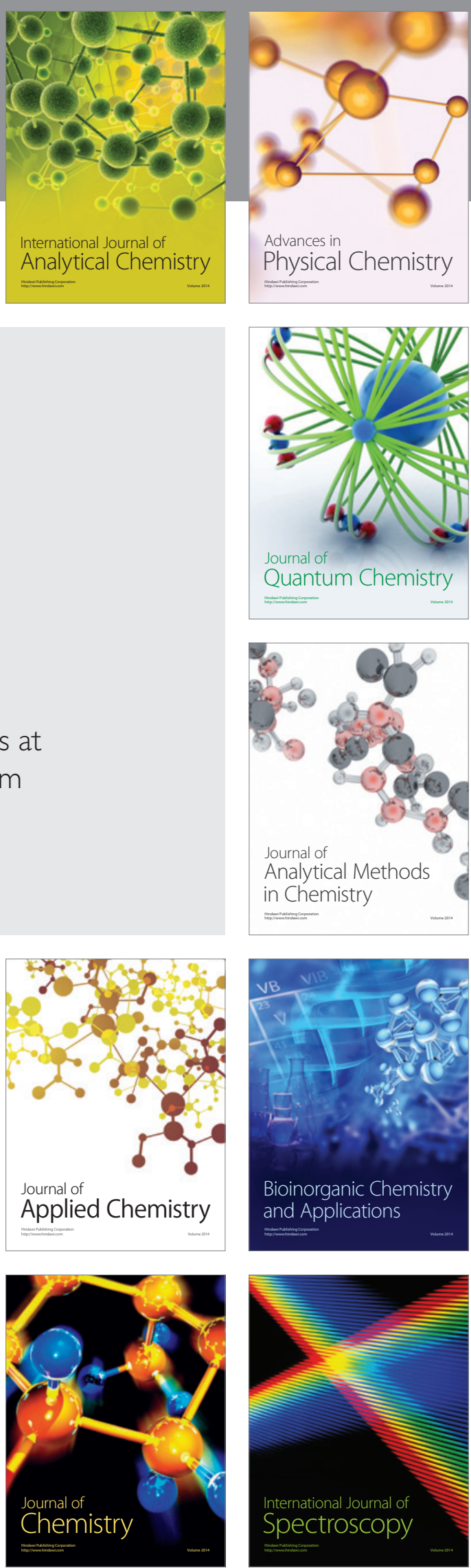